\title{
MANFAAT SERTIFIKASI PROFESI PENGELOLA KEARSIPAN DASAR PADA LSP P1 UI DALAM MENINGKATKAN KOMPETENSI LULUSAN PROGRAM STUDI MANAJEMEN INFORMASI DOKUMEN PROGRAM PENDIDIKAN VOKASI UI
}

\author{
Dyah Safitri \\ Program Studi Manajemen Informasi dan Dokumen \\ Program Pendidikan Vokasi Universitas Indonesia \\ dyah.mid@gmail.com/dyah.s@ui.ac.id
}

\begin{abstract}
Managing records requires high skills and therefore requires the competence of record manager. The skill level can be proven through professional certification test. Professional certification is issued by LSP as an extension of BNSP (National Agency for Professional Certification). P1 certification can be held by educational institutions including the University by conducting a series of certification tests. This research objectives is to find out the benefits of professional P1 certification held by LSP UI for MID Study Program graduates. This study uses a quantitative method by conducting an online survey involving graduates from the 2014 and 2015 MID study programs who have graduated from the study program and have professional certification. Limitation of Research This study covers only MID students class of 2014 and 2015 so it couldn't describe other courses. Research Findings The results of this study will show the benefits of professional certification. Another result is the possibility of the respondent continuing the certification test after the certificate expires (3 years) and must be updated.
\end{abstract}

Keywords: LSP UI, P1, certification test, MID Study Program, Vocational Education Program UI

\section{Intisari}

Mengelola arsip memerlukan keterampilan tinggi sehingga membutuhkan kompetensi pengelola arsip. Tingkat keterampilan tersebut dapat dibuktikan melalui uji sertifikasi profesi. Sertifikasi profesi dikeluarkan oleh LSP (Lembaga Sertifikasi Profesi) sebagai perpanjangan tangan dari BNSP (Badan Nasional Serfikasi Profesi). Sertifikasi P1 (pihak kesatu) dapat diadakan oleh lembaga pendidikan termasuk Universitas dengan melakukan serangkaian uji sertifikasi yang ketat. Tujuan Penelitian ini untuk mengetahui manfaat sertifikasi profesi P1 yang diadakan oleh LSP UI bagi lulusan Prodi MID. Penelitian ini menggunakan metode kuantitatif dengan melakukan survei online melibatkan responden lulusan program studi MID angkatan 2014 dan 2015 yang sudah sudah lulus dari program studi dan memiliki sertifikasi profesi. Batasan Penelitian Penelitian ini hanya mencakup mahasiswa MID angkatan 2015-2016 sehingga tidak dapat menggambarkan program studi lainnya. Temuan Penelitian Hasil studi ini akan memperlihatkan manfaat dari sertifikasi profesi. Hasil lainnya adalah kemungkinan responden melanjutkan uji sertifikasi di LSP P3 UI setelah masa berlaku sertifikat habis ( 3 tahun) dan harus diperbarui.

Kata kunci: LSP UI, P1, uji sertifikasi, Prodi MID, Program Pendidikan Vokasi UI 


\section{PENDAHULUAN}

Kebutuhan pada sumber daya manusia yang memiliki profesionalisme dan kompetensi saat ini menjadi prasyarat bagi banyak profesi. Seperti di dunia kearsipan. Kompetensi profesional yang terwujud melalui sertifikasi profesi menjadi tolok ukur kemampuan sumber daya manusia dalam melaksanakan tugas atau pekerjaan secara kompeten dan profesional. Pada gilirannya, kompetensi profesional itu dapat digunakan untuk mengukur kinerja dan tingkat keberhasilan sebuah organisasi. Sebagai sarana bantu menyatakan kompetensi dan profesionalitas di bidangnya, sertifikasi profesi diberikan secara sistematis dan obyektif melalui uji kompetensi yang mengacu kepada standar kompetensi kerja baik yang bersifat nasional maupun internasional. Sertifikat kompetensi mendasarkan diri pada kompetensi seseorang yang merupakan refleksi sikap, pengetahuan, keterampilan atau keahlian, dan penerapannya dalam melakukan pekerjaannya secara efektif dan efisien sesuai standar yang dipersyaratkan sehingga pekerjaan dapat dilaksanakan tepat waktu, tepat mutu, dan aman.

Di Indonesia, sertifikasi kompetensi dikeluarkan oleh BNSP (Badan Nasional Sertifikasi Profesi) yang merupakan badan independen langsung di bawah Presiden. BNSP memiliki kewenangan sebagai otoritas sertifikasi personil dan bertugas melaksanakan sertifikasi kompetensi profesi bagi tenaga kerja. BSNP menjadi bagian integral dalam sistem penyiapan tenaga kerja yang berkualitas. Sistem penyiapan tenaga kerja dalam format paradigma baru terdapat dua prinsip yang menjadi dasarnya, yaitu penyiapan tenaga kerja didasarkan atas kebutuhan pengguna (demand driven) dan proses diklat sebagai wahana penyiapan tenaga kerja dilakukan dengan menggunakan pendekatan pelatihan berbasis kompetensi (Competency Based Training / CBT).

Dalam mendukung pelaksanaan sertifikasi tersebut, BNSP dapat memberikan lisensi kepada lembaga sertifikasi profesi (LSP) untuk melaksanakan sertifikasi kompetensi profesi atas nama BNSP. Lisensi tersebut diberikan setelah BNSP melakukan penilaian kesesuaian kepada LSP, sesuai dengan ketentuan BNSP. Sesuai Peraturan Badan Nasional Sertifikasi Profesi Nomor 2/BNSP/ III/2014, ada LSP P1 (pihak kesatu) lembaga pendidikan dan/atau pelatihan dengan tujuan utama melaksanakan sertifikasi kompetensi kerja terhadap peserta pendidikan/pelatihan berbasis kompetensi dan /atau sumber daya manusia dari jejaring kerja lembaga induknya, sesuai ruang lingkup yang diberikan oleh BNSP. Fungsi dari LSP P1 diantaranya adalah menyusun dan mengembangkan skema sertifikasi, membuat perangkat asesmen dan materi uji kompetensi, menyediakan tenaga penguji (asesor), melaksanakan sertifikasi,hingga melakulan layanan sertifikasi. Sedangkan wewenangnya diantaranya adalah menerbitkan sertifikat kompetensi sesuai pedoman BNSP hingga mencabut atau membatalkan sertifikat kompetensi.

Program Pendidikan Vokasi UI melalui LSP UI sebagai LSP P1 (pihak kesatu) sudah melakukan sertifikasi mulai tahun 2017. Bagi lulusan Program Pendidikan Vokasi UI khususnya Program Studi Manajemen Informasi dan Dokumen, uji kompetensi profesi pengelola kearsipan dasar diwajibkan bagi semua mahasiswa yang akan lulus. Uji kompetensi pada 2017 ditujukan bagi seluruh mahasiswa angkatan 2014. Sedangkan uji kompetensi pada 2018 ditujukan bagi semua mahasiswa angkatan 2015. Jumlah total mahasiswa program studi 
Manajemen Informasi dan Dokumen Program Pendidikan Vokasi UI adalah 184 orang. Uji kompetensi ini rencananya akan dilakukan pula pada 2019 bagi angkatan 2016 yang akan lulus pada tahun ketiga mengenyam perkuliahan di Program Pendidikan Vokasi UI.

Dari latar belakang tersebut, menarik diteliti bagaimana mahasiswa Program Studi Manajemen Informasi dan Dokumen Program Pendidikan Vokasi UI angkatan 2014 dan 2015 memandang tentang sertifikasi profesi yang menjadi salah satu syarat kelulusan. Apakah sertifikasi tersebut bermanfaat untuk menunjang karir mereka, mudah mendapatkan pekerjaan, atau dapat mengukur standarisasi kemampuan mengelola arsip dasar.

Pertanyaan yang diajukan adalah :

1. Bagaimana mahasiswa MID angkatan 2014 dan 2015 memandang sertifikasi profesi yang dikeluarkan oleh LSP P1 Program Pendidikan Vokasi UI?

2. Bagaimana dengan sertifikasi profesi tersebut dapat menjadi standar pengetahuan dan keterampilan dalam pengelolaan kearsipan dasar?

3. Apakah mereka akan melanjutkan sertifikasi profesi selanjutnya bila ada kesempatan?

Tujuan praktis dalam penelitian ini adalah untuk mengetahui bagaimana pandangan mahasiswa program studi manajemen informasi dan dokumen angkatan 2014 dan 2015 memandang sertifikasi profesi yang diadakan LSP P1 Vokasi UI. Tujuan teoritisnya adalah menyediakan sumbangan teoritis terhadap kompetensi profesi sebagai bagian dari penerapan pengajaran yang berorientasi pada dunia kerja di Program Pendidikan Vokasi khususnya Program Studi Manajemen Informasi dan Dokumen.

Penelitian ini hanya menggunakan populasi dari mahasiswa MID angkatan 2014 dan 2015 sehingga dapat diterapkan terbatas pada angkatan tersebut.

Ketika dunia kerja semakin kompetitif maka untuk melihat profesionalisme, tingkat keterampilan, pengalaman, dan pemahaman terhadap pekerjaan, maka sertifikasi profesi dapat menjadi jawabannya. (Philips, John T, 2004). Menurutnya, di dunia kearsipan sertifikasi profesi akan berpengaruh pada kredibilitas dan keefektifan organisasi. Sertifikasi profesi menunjukkan kompetensi profesional. Dalam catatan Philips, setidaknya ada 900 sertifikat profesi kearsipan di seluruh dunia pada waktu itu. Artinya, saat ini jumlahnya dapat meningkat secara signifikan terutama saat arsip berbasis elektronik banyak digunakan.

Penyebab para pengelola arsip harus mendapatkan sertifikasi adalah permintaan dari pengguna, sebagai salah satu cara untuk mengenalkan prosedur kerja dan transparansi dalam mendapatkan pandangan manajemen yang lebih luas. Keuntungan utama dari sertifikasi profesi adalah perbaikan manajemen yang bertemu dengan otoritas publik sehingga prosedur kerja makin disiplin dan meningkatnya kemampuan penjejakan (traceability). (Gunnlaugsdottir, Johanna, 2012). Survei yang dilakukan Gunnlaugsdottir pada perusahaan-perusahaan Islandia memberi makna pada pengelola arsip dan peneliti bahwa lingkungannya tidak jauh berbeda dengan apa yang terjadi di Eropa Barat. Sehingga, pengelolaan arsip yang tersertifikasi akan memberikan dampak positif bagi kinerja perusahaanperusahaan termasuk di Islandia dan negara Eropa Barat lainnya yang memiliki fasilitas tak jauh berbeda.

Di Amerika Serikat, CRM (Certi6ied Records Manager) yang dikeluarkan oleh ICRM (Institute Certified Records Manager) menggambarkan sebuah standar bagaimana seseorang terlibat dalam kegiatan arsip dan manajemen 
informasi yang dapat terukur, terakreditasi, dan dikenal menurut kriteria pengalaman dan kapabilitas dari koleganya (Read dan Ginn,2011). Beberapa tes pengetahuan tentang arsip dan kefasihan dalam manajemen arsip diujikan dalam sertifikasi kompetensi CRM. Ada enam bagian tes yaitu prinsip manajemen dan program manajemen arsip dan informasi, penciptaan dan penggunaan arsip, sistem kearsipan, penyimpanan, dan temu kembali; penilaian, retensi, proteksi, dan pembuangan arsip; fasilitas dan teknologi, serta studi kasus.

Tujuan dari sertifikasi kearsipan ini adalah memunculkan standar profesi dengan pengetahuan yang diharapkan seimbang antara pendidikan formal, pengalaman pekerjaan, dan kebutuhan pada pendidikan lebih lanjut. Sertifikat profesi kearsipan CRM ini mengharuskan 100 jam pendidikan dalam lima tahun untuk memperpanjang status dari CRM. Proses ini dianggap vital bagi kredibilitas dari sertifikasi profesi CRM karena banyak tantangan yang akan dihadapi oleh pekerja kearsipan di masa datang. (Philips, John T, 2004)

Beberapa contoh tersebut berada di negara seperti Eropa dan Amerika Serikat. Bagaimana dengan Indonesia dan negara tetangga seperti Malaysia. Di Malaysia, profesi arsiparis masih belum dianggap sebagai sebuah profesi tersendiri. (Ismail, Aliza dan Adnan Jamaludin, 2009).Penelitian terhadap enam BUMN Malaysia menunjukkan bahwa pengelolaan arsip belum mejadi bagian dari struktur organisasi di Malaysia. Nama arsiparis hanyalah predikat bagi profesi yang bekerja di Arsip Nasional sedangkan yang bekerja di perusahaan-perusahaan bukan spesifik sebagai arsiparis. Sehingga, uji kompetensi profesi masih belum menjadi kebutuhan di Malaysia.

\begin{tabular}{lrr}
\multicolumn{2}{c}{ Sedangkan menurut } & Mawanda, \\
Akbar Hiznu (2018) & sertifikasi \\
kompetensi sumber daya & manusia
\end{tabular}

seharusnya menimbulkan aura positif dalam pelaksanaan sertifikasi kompetensi di Indonesia sehingga sumber daya manusia Indonesia makin kompetitif dan siap dalam persaingan di pasar bebas. Karena itu, pentingnya posisi sertifikat kompetensi ini, jelas diperlukan terobosan cerdas agar pelaksanaan sertifikasi kompetensi berjalan dengan cepat, terjangkau, tetapi tetap terjaga kualitasnya. Dalam prakteknya, BNSP dapat memberikan lisensi kepada lembaga sertifikasi profesi (LSP) untuk melaksanakan sertifikasi kompetensi profesi atas nama BNSP. Seperti yang diperoleh LSP Vokasi UI sebagai lembaga pendidikan untuk menjadi LSP P1 (pihak kesatu) dengan tujuan melaksanakan sertifikasi kompetensi kerja terhadap peserta pendidikan/pelatihan berbasis kompetensi dan /atau sumber daya manusia dari jejaring kerja lembaga induknya, sesuai ruang lingkup yang diberikan oleh BNSP. Bagi mahasiswa program studi manajemen informasi dan dokumen Program Pendidikan Vokasi UI, uji sertifikasi kompetensi ini sudah dilakukan sejak 2017 dan berlanjut pada 2018 dengan melibatkan total 184 orang yang telah mengikuti uji sertifikasi profesi tersebut.

\section{METODOLOGI}

\section{Desain Penelitian}

Penelitian ini menggunakan metode kuantitatif untuk menggambarkan bagaimana pandangan mahasiswa MID angkatan 2014 dan 2015 yang telah mengikuti uji kompetensi profesi pada 2017 dan 2018 yang lalu. Riset kuantitatif kerap disebut sebagai metode tradisional, positivistik, hingga metode saintifik,. Metode kuantitatif dapat diinterpretasikan sebagai metode riset berbasis filsafat positivism menggunakan populasi atau sampel. Data dalam penelitian ini menggunakan metode survey terhadap keseluruhan populasi 
menggunakan serangkaian pertanyaan sebagai dasar dari pengumpulan data.

\section{Objek dan Lokasi Penelitian}

Penelitian ini menggunakan obyek adalah mahasiswa MID angkatan 2014 dan 2015 yang sudah lulus dari Program Studi Manajemen Informasi dan Dokumen Program Pendidikan Vokasi UI.

\section{Populasi}

Populasi dalam penelitian ini adalah seluruh mahasiswa MID angkatan 2014 dan 2015 yang sudah lulus uji kompetensi profesi kearsipan. Jumlahnya adalah 184 mahasiswa.

\section{Tipe danSumber Data}

Data yang digunakan adalah data primer. Data tersebut didapatkan dari hasil kuesioner yang disebar ke seluruh mahasiswa MID angkatan 2014 dan 2015 tentang pandangan mereka terhadap uji kompetensi profesi untuk mendapatkan sertifikasi profesi yang sudah dilaksanakan pada 2017 dan 2018 yang lalu.

\section{Teknik Pengumpulan Data}

Metode pengumpulan data adalah melalui survei online menggunakan Google Docs. Semua anggota populasi mengisi kuesioner yang disebarkan secara online. Distribusi kuesioner juga dilakukan secara online dan populasi dapat menjawab melalui sarana yang ada seperti komputer ataupun telepon seluler.

\section{HASIL DAN PEMBAHASAN Profil Responden}

Pada penelitian ini, responden lebih banyak dari angkatan 2014 yakni 63,2\% dan angkatan 2015 36,8 \%. Angkatan 2014 Program Studi Manajemen Informasi dan Dokumen memang jumlahnya lebih banyak dari angkatan 2015.

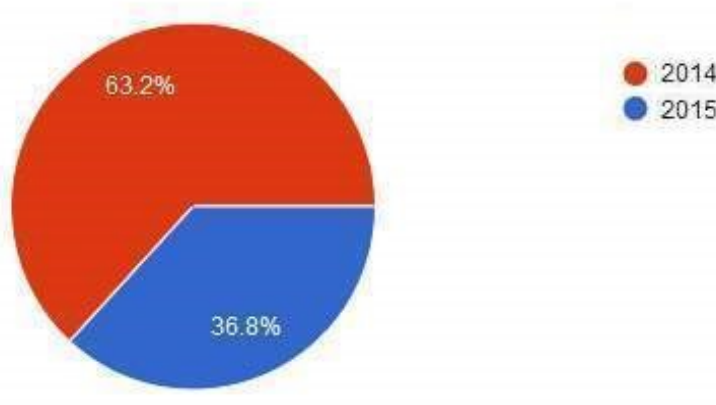

Gambar 1. Proporsi responden per angkatan

Sebelum uji kompetensi profesi, diadakan bimtek atau bimbingan teknis sebagai pengenalan terhadap uji kompetensi pengelolaan kearsipan dasar. Tidak seluruh responden mengikuti bimbingan teknis. Hasil yang diperoleh adalah 57,9\% mengikuti bimtek pada 2017, sementara $42,1 \%$ responden mengikuti bimtek pada 2018

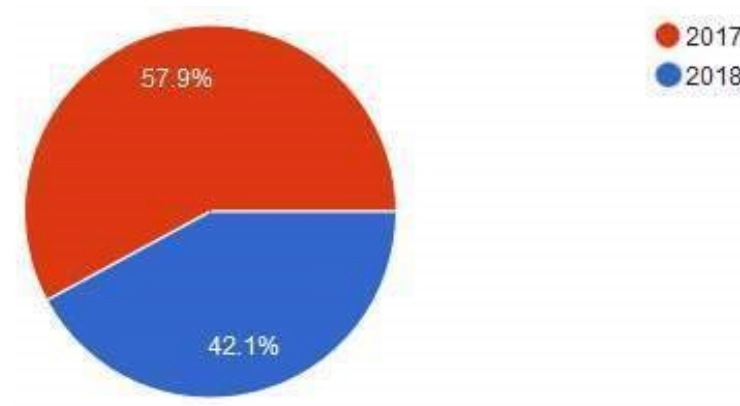

Gambar 2. Persentase yang mengikuti Bimtek Uji Kompetensi Kearsipan Dasar

Dari seluruh responden, mayoritas sudah bekerja sebagai karyawan $52,6 \%$ dan $15,8 \%$ mendeklarasikan diri sebagai pengusaha. Sementara sisanya melanjutkan pendidikannya ke strata yang lebih tinggi. 


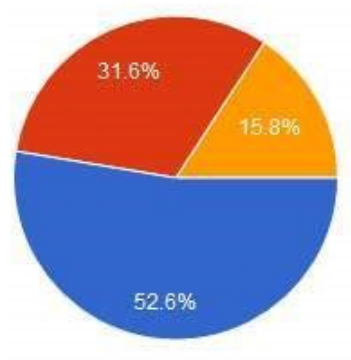

Gambar 3. Persentase kegiatan responden saat ini.

\section{Respon Terhadap Sertifikasi Profesi}

Uji kompetensi pada sertifikasi profesi dianggap sangat bermanfaat bagi mahasiswa program studi manajemen informasi dan dokumen angkatan 2014 dan 2015. Ada 92,1\% responden mengatakan bahwa ujian sertifikasi LSP P1 bermanfaat bagi mereka. Sisanya 7,9\% mengaku tidak bermanfaat.

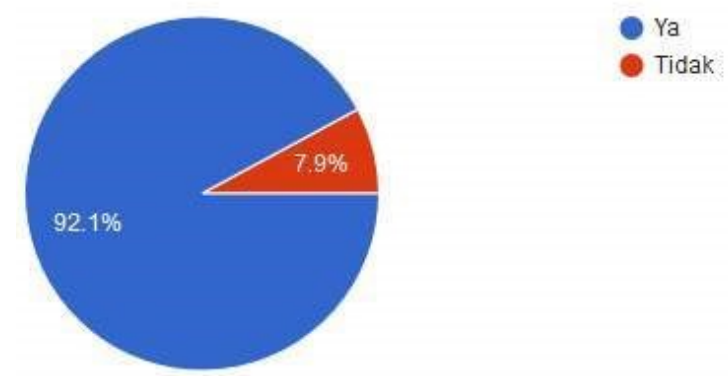

Gambar 4. Apakah uji sertifikasi bermanfaat bagi responden

Manfaat dari uji sertifikasi ini bagi responden paling banyak karena kemampuan kearsipan menjadi terstandarisasi $\quad(76,3 \%), \quad$ sebagai penunjang dalam kehidupan karir $(57,9 \%)$, dapat memenuhi persyaratan kerja (50\%), dan lebih mudah mendapatkan pekerjaan $(23,7 \%)$.

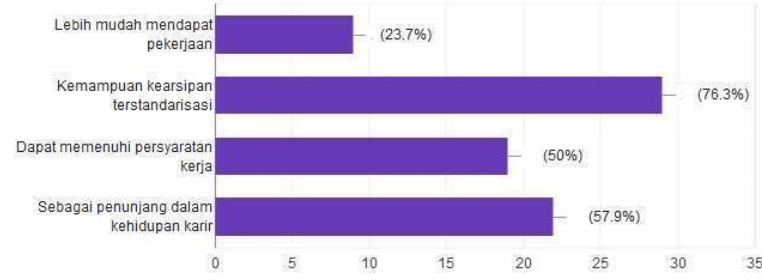

Gambar 5. Manfaat yang dirasakan dari uji sertifikasi kompetensi

Apabila dikaitkan dengan pekerjaan, apakah sertifikasi profesi dari LSP P1 Pengelolaan Kearsipan Dasar dapat menunjang karir, ada 50\% menyatakan tegas ada hubungannya, 42,1 menyatakan mungkin ada hubungannya, sedangkan $7,9 \%$ menyatakan tidak ada hubungan sama sekali sertifikasi tersebut dengan pekerjaan yang mereka geluti.

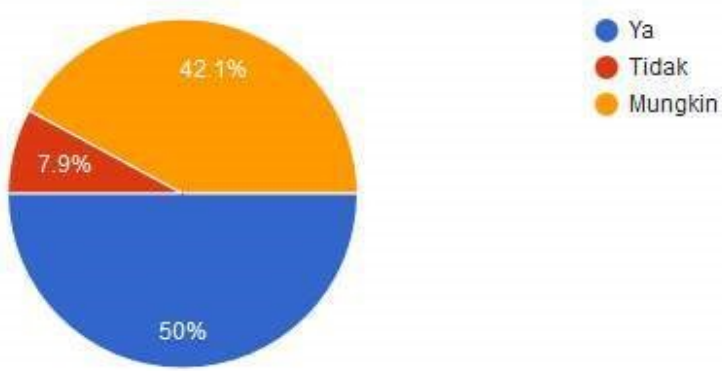

Gambar 6. Sertifikasi Profesi dari LSP P1 Dalam Menunjang Karir

Sementara ketika ditanyakan mengenai apakah sertifikasi profesi yang mereka ikuti sesuai dengan kebutuhan pada dunia kerja. Ada jawaban tegas ya dari 47,4\% responden. Sedangkan yang masih ragu karena menjawab mungkin adalah $44,7 \%$ dan sisanya $7,9 \%$ menyatakan tidak sesuai dengan kebutuhan kerja.

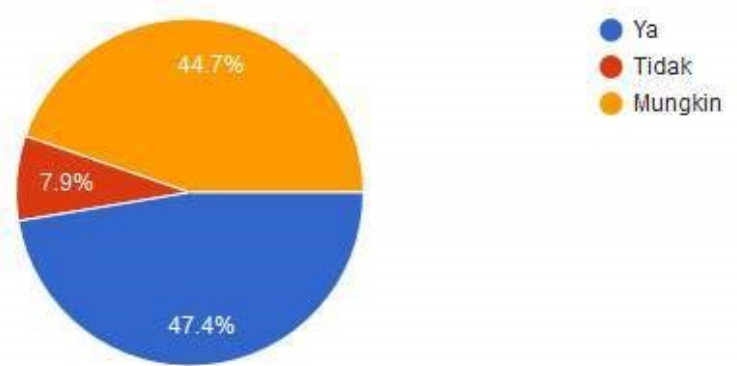

Gambar 7. Sertifikasi Profesi dari LSP P1 Yang diikuti Sesuai Dengan Kebutuhan Kerja 
Ketika disodorkan pertanyaan mengenai kemungkinan mahasiswa angkatan 2014 dan 2015 Program Studi MID Program Pendidikan Vokasi UI mengikuti sertifikasi profesi lanjutan, ada $47,4 \%$ yang menyatakan tegas ikut. $50 \%$ menyatakan mungkin akan mengikuti, sedangkan 2,6\% menyatakan tidak akan mengikuti sertifikasi profesi lanjutan.

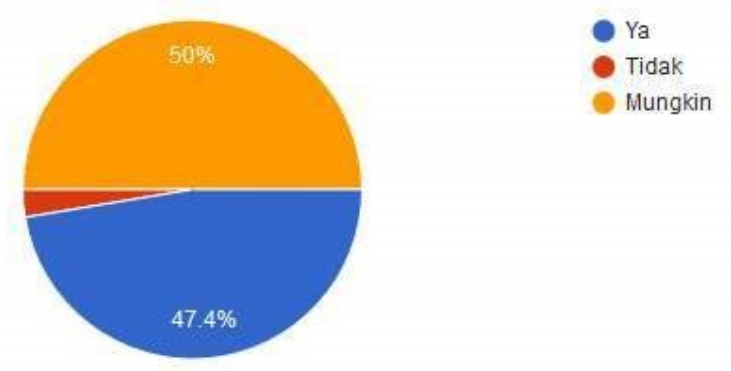

\section{Gambar 8. Minat Terhadap Sertifikasi Lanjutan}

\section{KESIMPULAN}

Jawaban yang diberikan responden memberikan gambaran bagaimana mahasiswa program studi MID Program Pendidikan Vokasi angkatan 2014 dan 2015 memandang uji sertifikasi profesi.. Dari jawaban tersebut dapat disimpulkan bahwa mereka mengakui bahwa sertifikasi profesi yang menerangkan kompetensi pengelolaan kearsipan dasar dapat membantu mereka dalam banyak hal seperti standarisasi kemampuan pengelolaan arsip hingga sebagai penunjang dalam karir pekerjaan mereka. Sertifikasi profesi memang dapat menunjang karir walaupun cukup banyak pula yang ragu sertifikasi profesi ini bermanfaat nantinya dalam karir pekerjaan mereka.

Uji sertifikasi yang biasa berlaku dalam kurun waktu tertentu dan harus diperbarui untuk mendapatkan sertifikasi profesi yang baru menyiratkan untuk kemampuan lulusan program studi MID untuk mengikuti sertifikasi lanjutan. Hanya saja, pandangan lulusan terhadap sertifikasi lanjutan ini belum terlalu positif tentang pemahaman mengenai uji sertifikasi lanjutan ini agar mereka yang bekerja di dunia kearsipan dapat memperoleh pengakuan kompetensi yang disesuaikan dengan pengetahuan, keterampilan dan pengalaman pekerjaan mereka.

Dalam era kompetisi yang kian ketat seperti saat ini, memiliki sertifikasi profesi sebenarnya adalah sebuah nilai lebih terutama bagi lulusan yang baru saja menyelesaikan kuliahnya di Program Pendidikan Vokasi UI. Tapi, masih perlu banyak sosialisasi dan pemahaman mengenai sertifikasi ini karena tidak semua mengetahui manfaat yang dapat diberikan oleh sertifikat kompetensi. Bila sosialisasi gencar dilakukan, kegamangan untuk mendapatkan sertifikasi profesi pengelolaan kearsipan dasar bagi lulusan Program Studi MID dapat ditekan karena mereka akan timbul kesadaran sejak awal bahwa uji sertifikasi profesi dapat menunjang karirnya kelak ketika mereka mulai masuk dan bekerja sebagai pengelola kearsipan di sebuah organisasi

\section{Daftar Pustaka}

Akbar Hiznu Mawanda (2018). Sertifikasi Kompetensi SDM. Harian Kompas 16 Juli 2018. hal 7

Aliza Ismail dan Adnan Jamaludin (2011). Records Professional : an invisible profession in Malaysia. Record Management Journal vol. 65 No. 1

Badan Nasional Sertifikasi Profesi. www.bnsp.go.id diakses pada 5 September 2018

Johanna Gunnlaugsdottir (2012). Information and Records Management A Precondition for a well-functioning quality management system. Journal of Records Management. Vol.66 no.7

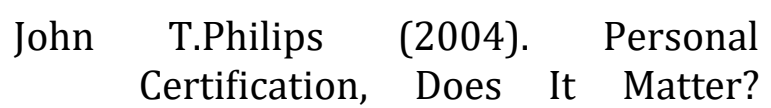


Information Management Journal. Nov/Des 2004. Vol.38 No.6

Peraturan Badan Nasional Sertifikasi Profesi Nomor 2/BNSP/III/2014 tentang LSP (Lembaga Sertifikasi Profesi)

Read, Judith dan Mary Lea Ginn (2011). Records Management $9^{\text {th }}$ edition, Mason : South-Western Cengage Learning 